\title{
REVISTA
}

\section{A PANDEMIA DA COVID-19 E O ENSINO REMOTO: COMO LECIONAR CONTABILIDADE SOCIETÁRIA DE FORMA EFICAZ?}

\author{
THE COVID-19 PANDEMIC AND REMOTE EDUCATION: HOW TO TEACH \\ CORPORATE ACCOUNTING EFFECTIVELY?
}

\author{
Thiago Boldrini \\ Fucape Business School. E-mail: thiago.boldrini@ifes.edu.br
}

Artigo submetido em 21/01/2021, aceito em 05/04/2021 e publicado em 28/05/2021.

Resumo: A pandemia da Covid-19 causada pelo novo Coronavírus obrigou o mundo inteiro a realizar mudanças, inclusive na educação. De forma repentina, as aulas presenciais foram substituídas pelo ensino remoto não presencial, sem que houvesse um planejamento adequado para isso. Por outro lado, o ensino de contabilidade vem sofrendo inúmeras críticas nos últimos anos tanto pelo que é ensinado como pelo como é ensinado. No caso da disciplina de contabilidade societária, a situação é ainda pior: agrava-se pela ausência de pesquisas amplas sobre sua metodologia. $\mathrm{O}$ presente artigo propõe-se a oferecer possibilidades de soluções para a seguinte questão: durante a pandemia da Covid-19 e o ensino remoto, como lecionar contabilidade societária de forma eficaz? Como solução, recomendamos aos docentes da disciplina, trabalhar com metodologias ativas de aprendizagem, especificamente a aprendizagem baseada em problemas, aprendizagem baseada em times e sala de aula invertida.

Palavras-chave: Educação Contábil; Ensino de Contabilidade Societária; Metodologias Ativas.

\begin{abstract}
The Covid-19 pandemic caused by the new Coronavirus forced the entire world to make changes, including in education. Suddenly, face-to-face classes were replaced by remote, non-face-toface teaching, without adequate planning for this. On the other hand, accounting education has been subject to numerous criticisms in recent years, both for what is taught and for how it is taught. In the case of corporate accounting discipline, the situation is even worse: it is aggravated by the absence of extensive research on its methodology. This recommendation article proposes to offer possibilities for solutions to the following question: during the Covid-19 pandemic and remote education, how to teach corporate accounting effectively? As a solution, we recommend that teachers of the discipline, work with active learning methodologies, specifically problem-based learning, team-based learning and inverted classroom.
\end{abstract}

Keywords: Accounting Education; Teaching of Corporate Accounting; Active Methodologies.

\section{INTRODUÇÃO}

O novo Coronavírus, causador da Covid-19, descoberto em dezembro de 2019 em Wuhan, China, iniciou uma pandemia mundial, causando infecções que variam da forma assintomática a mortalidade crítica, especialmente em grupos mais vulneráveis, como adultos imunocomprometidos (ABDULAMIR e HAFIDH, 2020). Portanto, em 2020, o mundo iniciou um período de terror, que parece ficção científica: a doença 
espalhou-se rapidamente, não discriminando grau de democracia, finanças, gênero, etnia ou religião (USAK et al., 2020).

A pandemia forçou muitas organizações a passarem por transformações significativas, repensando elementos chave de seus processos de negócios e o uso de tecnologia para manter suas operações, ao mesmo tempo que aderiram a um cenário de mudança de diretrizes e novos procedimentos (DWIVEDI et al., 2020). Como consequência, houve o fechamento de escolas em diversos países, independente da inexistência de evidências científicas para esta prática (VINER et al., 2020). Todos os níveis educacionais foram afetados, desde a pré-escola até a educação superior, sendo que a Unesco estima que cerca de 900 milhões de alunos foram afetados pelo fechamento das instituições educacionais ao redor do planeta entre 2019 e 2020 (NICOLA et al., 2020).

Com a situação de isolamento social decorrente da pandemia, novas modalidades de ensino precisaram ser adotadas, fazendo com que o ensino remoto emergencial, ou simplesmente ensino remoto, ganhasse força nas instituições de ensino. Essa forma de ensino, conforme defendido por Whittle et al. (2020), oferece suporte instrucional temporário desenvolvido rapidamente em uma crise, sem recursos ou infraestrutura planejados.

Mesmo sabendo que a intensidade do uso de ferramentas virtuais no meio acadêmico já vinha aumentando nos últimos anos, conforme destacado por Meurer et al. (2020), é uma mudança enorme e perturbadora transformar cursos presenciais em on-line em questão de dias, sem haver projetos, materiais e suportes adequados (BAO, 2020). Toda experiência anterior com tecnologia na educação agora ganhou uma importância inimaginável até então.
Neste mesmo momento histórico, a educação contábil continua a ser criticada em função da falta de atualização e da abordagem excessivamente tecnicista, com metodologias essencialmente tradicionais. Os avanços da tecnologia transformaram a pesquisa acadêmica e as publicações, porém não mudaram significantemente $o$ que é ensinado ou como é ensinado (PINCUS et al., 2017), o que cria, iminentemente, um conflito com a era do ensino remoto, que passou a ganhar destaque.

Continua-se a viver, na academia, uma realidade distante do que um mundo na era da indústria 4.0 cobra dos profissionais, corroborando por destacar as dificuldades de adequação às novas ferramentas de ensino. Asonitou e Hassal (2019) imperam que há a necessidade de aprimorar as habilidades de pensamento crítico dos futuros contadores por meio de novas abordagens de ensino e do desenvolvimento de um currículo que apoie a empregabilidade e o desenvolvimento sustentável dos graduandos.

O ensino de contabilidade societária segue as mesmas tendências e dificuldades da própria educação contábil em geral. Tomando especificamente $\mathrm{o}$ ensino dos Pronunciamentos Técnicos (CPC), é possível perceber os problemas encontrados no ensino superior de Ciências Contábeis. Martin et al. (2017) destacaram, em seus resultados, que os CPCs estão sendo introduzidos no processo de formação acadêmica, mas de forma superficial e suscinta, sendo que há consenso entre docentes e discentes de que não estão preparados para aplicar os conteúdos desses pronunciamentos.

Conforme pesquisado por Alves et al. (2017), o ensino de contabilidade harmonizado aos padrões internacionais necessita de melhorias, contemplando um número maior de CPCs nas ementas e conteúdos programáticos das instituições de ensino superior. Trata-se de um 
problema específico, mas que pode ser estendido à toda área de contabilidade societária, onde cabe muito bem a análise de Asonitou e Hassal (2019), ao citarem que existe uma lacuna de expectativa de desempenho entre o mercado e os graduados dos departamentos de negócios e contabilidade.

Nessa abordagem, temos um problema decorrente da pandemia da Covid-19 e da adoção do ensino remoto, na perspectiva de um ensino de contabilidade antiquado, especificamente analisado em uma disciplina de grande importância no curso em questão: como ensinar contabilidade societária de forma eficaz? Este artigo de recomendação propõe estratégias de ensino baseadas em metodologias ativas para auxiliar o professor do curso de ciências contábeis a ministrar a disciplina de contabilidade societária de forma eficaz, possibilitando alcançar resultados satisfatórios.

Seguindo na perspectiva de Bozkurt e Sharma (2020), a educação a distância envolve muito mais que enviar conteúdo educacional, pois é um processo de aprendizado que fornece aos alunos responsabilidade, flexibilidade e escolha, ou seja, um complexo processo que requer planejamento cuidadoso, concepção e determinação de objetivos para criar uma cadeia de aprendizagem eficaz. Devido ao surgimento repentino da Covid-19, a maioria dos membros do corpo docente das universidades iniciou um processo de enfrentamento dos desafios da falta de experiência de ensino on-line, preparação antecipada ou suporte das equipes de tecnologia educacional (BAO, 2020).

A realidade é que, segundo Bozkurt e Sharma (2020), o ensino remoto sempre foi considerado uma alternativa ou opção flexível para os alunos, porém tornou-se uma obrigação de emergência, o que significa que estratégias e prioridades diferentes precisam ser adotadas. Destarte, buscar novas formas de ensinar durante essa fase torna-se algo fundamental, principalmente em uma matéria com a importância de contabilidade societária, objetivando alcançar uma eficácia satisfatória ao final do período letivo.

O ensino sob a perspectiva do construtivismo vem ganhando força nas últimas décadas. $\mathrm{O}$ ensino contábil tem despertado para a discussão sobre mudanças de paradigmas metodológicos, com fundamentação no ensino centrado na participação no processo de aprendizagem, nas quais o aluno torna-se o sujeito promotor do seu conhecimento a partir de metodologias ativas de aprendizagem (SILVA et al., 2018).

A partir desta visão pedagógica, o trabalho será desenvolvido na seguinte linha de raciocínio: um background com os ensinos remoto, contabilidade, contabilidade societária e metodologias ativas; discussão de pontos de vista relacionados a temática; análise de três metodologias ativas colaborativas (aprendizagem baseada em problemas, aprendizagem baseada em times e sala de aula invertida); e a apresentação da proposta de resolução do problema em análise.

\section{BACKGROUND}

\subsection{ENSINO REMOTO}

O ensino não presencial é algo que não é novidade no meio acadêmico, especialmente no ensino superior. Várias são as formas em que se apresentou nos últimos anos e já era uma tendência para os próximos tempos, independente da pandemia instaurada. $\mathrm{O}$ ensino remoto, em especial, acabou por ser a modalidade utilizada por muitas instituições, devido ao caráter emergencial da situação.

O ensino remoto não é sinônimo de educação a distância $(\mathrm{EaD})$. $\mathrm{Na} \mathrm{EaD}$, todo o processo é concebido para ser desenvolvido de forma não presencial, com o apoio da tecnologia. Todo o processo é pensado na concepção da conectividade do 
aluno, incluindo professores, polos de ensino e material pedagógico. Em contrapartida, no ensino remoto, devido a seu caráter emergencial, o ensino presencial é aplicado na modalidade à distância, sem concepção para tal finalidade.

Em virtude do caráter de improviso do momento educacional, inúmeros problemas tendem a surgir, porquanto é algo simplesmente adaptado. Nesse sentido, Silveira et al. (2020) destacam que os docentes de diferentes instituições estão desenvolvendo atualmente o ensino remoto e não a $\mathrm{EaD}$, até mesmo porque a maioria das instituições de ensino, que atuam na modalidade presencial, não possuem infraestrutura tecnológica para dar suporte às atividades em $\mathrm{EaD}$ e não prepararam seus docentes para atuarem neste contexto.

\subsection{ENSINO DE CONTABILIDADE}

O ensino de contabilidade, historicamente, baseia-se na concepção e prática de conceitos técnicos, onde aprende-se a fazer de forma precisa, porém mecânica. Até então, não há muito espaço para a formação reflexiva, muitas vezes em razão do caráter da própria profissão, conseguinte da formação do professor que atua na disciplina.

A educação, como um todo, vive um momento de revolução, primordialmente em razão da revolução tecnológica que o mundo presencia. A era da indústria 4.0, com o advento da inteligência artificial, faz com que tudo precise ser resolvido no menor tempo possível, de forma conectada. Não há espaço para o engessamento de funções. Asonitou e Hassall (2019) reforçam que o graduado em contabilidade no século XXI não tenha as habilidades como um mecanismo de rotina, mas sim como um processo que irá equipá-lo com visão, ambições, autoconfiança e criatividade.

Doravante, críticas surgem de forma inevitável, conseguinte ao caráter de dificuldade das transformações. A inovação do currículo de contabilidade representa um desafio assustador e significativo que muitas vezes fica aquém dos objetivos prioritários para todos os programas de contabilidade (BALLOU et al., 2018).

Nessa análise, os gestores e professores precisam transformar a graduação em ciências contábeis, visando uma formação mais adequada e alinhada com o mundo tecnológico contemporâneo. Sledgianowski et al. (2017) corroboram ao afirmar que discutir os sistemas de informação e competências tecnológicas dentro do contexto de um curso de contabilidade permite que os educadores identifiquem as aplicações das competências específicas que todos os alunos de um programa ficam expostos, proporcionando-lhes as mesmas oportunidades de aquisição de competência.

Assim, a pedagogia contábil vem sendo imersa em um processo de críticas por excesso de tecnicismo e falta de evolução, além de muita pressão por parte do mercado para se alinhar com as demandas atuais. No contexto da pandemia causada pelo Coronavírus e adoção do ensino remoto, todo o processo de ensino e aprendizado adentrou a um período ainda mais conturbado. Doravante, a educação contábil vive um momento de dificuldades e necessita de uma revisão urgente.

\subsection{ENSINO DE CONTABILIDADE SOCIETÁRIA}

A contabilidade societária, conforme as necessidades do mercado e da sociedade, foi se adaptando e mutando no decorrer dos anos, até chegar ao que conhecemos hoje. Tem-se os primeiros registros com o decreto 2.627 , de 26 de dezembro de 1940, mas somente com a Lei $\mathrm{n}^{\circ}$ 11.638, de 28 de dezembro de 2007, ganha a formalidade e consistência atuais. 
Trata-se de um ramo da contabilidade de suma importância no mundo corporativo.

Contudo, há raríssimos registros de pesquisas relacionadas ao ensino de contabilidade societária dentro da educação contábil, mesmo com a reconhecida importância da disciplina. Mais uma vez, reflete-se o problema crônico da contabilidade: desconexão com o ensino reflexivo e excesso de conhecimento técnico. Os estudos de Martin et al. (2017) e Alves et al. (2017) são exemplos raros destas investigações.

Por se tratar de uma disciplina complexa, a contabilidade societária carece de atenção constante e interação demasiada com o professor e colegas de turma. A pandemia da Covid-19 tornou o aprendizado de todas as áreas algo mais complexo com a adoção do ensino remoto, o que implica em problemas de mesma intensidade, talvez até maiores, no estudo da referida disciplina.

\subsection{METODOLOGIAS ATIVAS}

$\mathrm{Na}$ visão de Lovato et al. (2018), metodologias ativas de aprendizagem são metodologias nas quais o aluno é o protagonista central, enquanto professores são mediadores ou facilitadores do processo, sendo que o aluno é instigado a participar da aula, por trabalhos em grupo ou discussão de problemas. Essa visão permite que o estudante, em qualquer modalidade de ensino, participe ativamente do processo, não apenas recebendo informações e ou sendo treinado para repetição.

As metodologias ativas podem ser divididas em colaborativas e cooperativas, sendo que a principal diferença entre elas reside no fato de a primeira não permitir hierarquias no processo, ao contrário da segunda. Segundo Lovato et al. (2018), os principais tipos de metodologias ativas colaborativas são a aprendizagem baseada em problemas, a problematização, aprendizagem baseada em projetos, aprendizagem baseada em times, sala de aula invertida e instrução por pares, enquanto as metodologias ativas cooperativas são jigsaw, divisão dos alunos em equipes para o sucesso e torneio de jogos em equipes.

As metodologias ativas surgiram por necessidade do processo de ensino e aprendizagem, na busca da eficácia do processo. No intuito de construir o conhecimento e desenvolver habilidades e atitudes nas aulas, surgiram as metodologias ativas (NAGIB e SILVA, 2020).

\section{PONTOS DE VISTA}

Obter eficácia em um processo, seja qual for, é uma tarefa árdua. Em tempos de pandemia e para uma disciplina complexa como contabilidade societária, o objetivo torna-se ainda mais laborioso. Muitos pesquisadores têm visões importantes e distintas sobre o ensino de contabilidade, de forma geral e em societária, além da educação em período de ensino remoto.

Os posicionamentos em relação ao ensino de contabilidade geralmente são relacionados à currículo (o que é ensinado) e à pedagogia (como é ensinado). Atualmente, profissionais de contabilidade têm destacado a necessidade de os alunos de contabilidade terem habilidades em tecnologia e análise de dados para terem sucesso na profissão contábil (ANDIOLA et al., 2020). Todavia, para Ballou et al. (2018), o papel da análise de dados não parece ser bem compreendido por profissionais ou acadêmicos.

As críticas ao que é ensinado e sugestões são constantes. Ainda segundo Ballou et al. (2018), os programas de contabilidade devem considerar como garantir que seus graduados em contabilidade possuam as competências necessárias para o ambiente de decisão baseado em dados. O desafio para os departamentos acadêmicos de contabilidade é determinar as habilidades e 
ferramentas analíticas de dados que são relevantes para a profissão contábil e como e quando incorporar esses tópicos em um currículo já completo (DZURANIN et al., 2018).

Em relação à pedagogia dos cursos de contabilidade, são comuns visões relacionadas a formação do professor. Para Fleischman et al. (2017), na carreira docente, a satisfação é um constructo relevante a ser avaliado no que diz respeito à atração de indivíduos para a academia de contabilidade e retenção deles. Falta na literatura de educação contábil uma discussão sobre as habilidades sociais efetivamente ensinadas na graduação e se os membros do corpo docente são treinados para assumir essa responsabilidade (REBELE e PIERRE, 2019). Logo, em qualquer contexto, formação e preparo do professor são fundamentais para o desempenho satisfatório de uma disciplina.

Especificamente dentro de contabilidade societária, Martin et al. (2017) destacam que durante a realização da pesquisa bibliográfica para sua pesquisa, constatou-se escassez de trabalhos que abordassem o tema estudo ou ensino dos CPCs, de modo que grande parte dos estudos estavam relacionados à harmonização das normas e ao processo de convergência das mesma, todavia com outro enfoque. Conquanto, Alves et al. (2017) realçam as críticas em relação ao ensino de contabilidade societária, ao afirmarem que as evidências obtidas em sua pesquisa reforçam a necessidade de maior número de CPCs nas ementas e conteúdos programáticos das instituições de ensino superior. Percebe-se, portanto, que em um assunto chave como CPCs, tanto a pesquisa quanto o ensino precisam de mudança.

Ampliando a percepção, muitas são as visões sobre formato de ensino não presenciais. Chaurasia et al. (2018) fomentam que em comparação com as aulas tradicionais, o ensino e aprendizagem se tornam ainda mais desafiadores em configurações online, onde há uma proporção reduzida de professor para aluno, interações assíncronas e mais heterogeneidade.

Nesse contexto, Ribeiro e Souza (2020) comentam que alunos e professores são praticamente contundentes ao afirmarem que as aprendizagens são possíveis durante a pandemia, mas que não é a mesma coisa, visto que há uma diferença inevitável na situação que os alunos se encontram, sobretudo no que diz respeito a atividade remota no contexto vivido se comparado com as atividades presenciais. Dessarte, a pandemia impôs inúmeros desafios para todos os sujeitos da educação, que lutam para manter uma qualidade no processo educacional.

Posições diferentes são assumidas pelos mais diversos pesquisadores, tanto para a educação contábil, que já vinha em um processo de constantes críticas e pressão, em especial com a ausência de pesquisas e discussões sobre o ensino da contabilidade societária, como para o processo de educação remoto. Posto isso, a próxima seção investigará a análise de três metodologias ativas propostas futuramente como solução para o problema discutido até aqui.

\section{ANÁLISE}

Em um contexto de grande adversidade e sem planejamento antecipado, como no caso do ensino remoto, o uso de metodologias ativas pode proporcionar resultados melhores que metodologias tradicionais, quando utilizadas de forma correta. Para que a utilização de metodologias ativas tenha sucesso, além dos fatores relacionados ao docente (conhecimento do método, disposição para aplicação, definição do momento de aplicação), aqueles ligados aos discentes (disposição para estudar por meio de uma nova metodologia) podem 
influenciar os resultados alcançados (NAGIB e SILVA, 2020).

Para subsídio da próxima seção, três metodologias ativas serão analisadas: aprendizagem baseada em problemas, sala de aula invertida e instrução por pares.

\subsection{APRENDIZAGEM BASEADA EM PROBLEMAS}

A aprendizagem baseada em problemas (problem-basead learning), PBL, é uma metodologia ativa comum na área de contabilidade, onde problemas são utilizados para a introdução, desenvolvimento e discussão de assuntos. Segundo Borochovicius e Tortella (2014), a PBL tem como premissa básica o uso de problemas da vida real para estimular o desenvolvimento conceitual, procedimental e atitudinal do discente.

De acordo com Barrows e Tamblyn (1980, apud LOVATO e LORETO, 2018), a PBL pode ser desenvolvida em cinco passos: 1) os alunos são apresentados a algum problema e organizam suas ideias, tentam definir o problema e solucioná-los com seus conhecimentos prévios, em grupo; 2) levantam questionamento de aprendizagem sobre os aspectos que não compreendem, após discussão; 3 ) planejam os modos como estas questões serão investigadas; 4) exploram as questões anteriores, fazendo usos de novos conhecimentos obtidos para a resolução do problema; 5) ao final, os alunos avaliam o processo, seus próprios desempenhos e de seus colegas. Esse método de ensino é prático e pode ser utilizado em quantidades variadas de alunos nos grupos, sendo uma vantagem a autoavaliação realizada na última etapa.

\subsection{APRENDIZAGEM BASEADA EM TIMES}

$\mathrm{Na}$ aprendizagem baseada em times (team-based learning), TBL, a turma é dividida em grupos que funcionam como times, onde os integrantes responderão a questões propostas pelo professor. É desejável que os alunos tenham conhecimento prévio sobre o assunto, logo leituras anteriores devem ser realizadas. As respostas dadas são apresentadas pela turma e discutidas, inclusiva com o professor. Trata-se de uma metodologia que estimula a colaboração entre os discentes, de forma mútua.

\subsection{SALA DE AULA INVERTIDA}

A sala de aula invertida é uma metodologia ativa que consiste exatamente em inverter os papeis da sala de aula e do estudo independente do discente: estuda em casa e discute o conteúdo em sala. Lovato e Loreto (2018) corroboram com a explanação ao asseverarem que a sala de aula invertida constitui uma modalidade de e-learning, com o conteúdo e as instruções sendo estudados pelos alunos de forma online e a sala de aula sendo o local para trabalhar os conteúdos já estudados de forma colaborativa.

A inversão do modelo tradicional de ensino provém de aulas menos expositivas, mais produtivas $\mathrm{e}$ participativas, de modo a engajar o educando e possibilitar uma melhor utilização do tempo para todos os envolvidos no processo (FELCHER et al., 2021). Nessa abordagem, Valente (2014) defende que como o aluno estuda antes, a aula se torna o lugar de aprendizagem ativa, onde há perguntas, discussões e atividades práticas.

\section{RECOMENDAÇÃO}

O mundo vive o momento da educação remota e aulas presenciais foram transformadas para a modalidade a distância, de forma repentina. Nenhum sujeito da educação estava preparado e tudo simplesmente aconteceu. Por outro lado, o ensino de contabilidade, ainda 
muito engessado, vem recebendo críticas para atualização (seja pelo currículo ou atuação docente, em virtude de sua formação inadequada do ponto de vista pedagógico) e pressão por parte do mercado, que presencia a revolução tecnológica da indústria 4.0.

Em uma terceira via, não necessariamente independente, o ensino de uma disciplina complexa e valorosa como contabilidade societária sofre com a falta de pesquisas e pensamentos críticos relacionadas a estratégias de ensino. Temse uma situação de questionamento de como lecionar contabilidade societária de forma eficaz durante o ensino remoto decorrente da pandemia da Covid-19.

As metodologias ativas de aprendizagem correspondem a uma forma atual de ensino, atrelada inclusive ao uso de tecnologias digitais. Propõe-se como recomendação aos docentes da disciplina de contabilidade societária o ensino por meios dessas metodologias, especificamente a aprendizagem baseada em problemas, aprendizagem baseada em times e sala de aula invertida.

A PBL torna-se uma ferramenta importante por inserir o discente no mundo relacionado ao conteúdo estudado, de grande contextualização. As vias digitais já estimulam isso, devido ao acesso instantâneo a internet. As aulas podem ser desenvolvidas sem grandes dificuldades de forma virtual e muitos professores de contabilidade já estão familiarizados com o método.

A TBL pode ser considerada uma metodologia eficaz por estimular a participação em conjunto na sala, com o apoio de mídias sociais. Os times podem ser formados a partir de grupos em redes sociais, estimulando inclusive a interação perdida nesse período de aulas não presenciais. Especialmente durante as circunstâncias desafiadoras e traumáticas da Covid-19, integrar a mídia social para promover a autorreflexão e o crescimento da identidade pode ser importante e significativo para os alunos (GREENHOW e GALVIN, 2020).

Por fim, a sala de aula invertida é uma das metodologias ativas de maior relevância nos últimos tempos, devido a sua reconhecida eficácia. Apesar de os alunos não estarem fisicamente na sala de aula, estudar antes e debater durante as aulas online é uma forma importante de esclarecer pontos relevantes e desenvolver um aprendizado duradouro.

O período de pandemia afeta a todos, sendo praticamente impossível não sofrer seus efeitos. Todavia, as três metodologias citadas são possibilidades para que os docentes consigam um resultado mais eficaz nas aulas de contabilidade societária. Não correspondem à única forma de ensinar, mas certamente são recomendações relevantes para garantir que o discente alcance um melhor aproveitamento.

\section{REFERÊNCIAS}

ABDULAMIR, A. S., \& HAFIDH, R. R. (2020). The Possible Immunological Pathways for the Variable Immunopathogenesis of COVID--19 Infections among Healthy Adults, Elderly and Children. Electronic Journal of General Medicine, v. 17, n. 4, p. 202-220.

ALVES, D. S., KRONBAUER, C. A., OTT, E., \& THOMAZ, J. L. P. (2017). O ensino dos CPCs nos cursos de ciências contábeis em instituições de ensino superior do Brasil. Revista

Contemporânea de Contabilidade, v. 14, n. 32, p. 48-70.

ANDIOLA, L. M., MASTERS, E., \& NORMAN, C. (2020). Integrating technology and data analytic skills into the accounting curriculum: Accounting department leaders' experiences and insights. Journal of Accounting Education, 50, 100655. 
ASONITOU, S., \& HASSALL, T. (2019). Which skills and competences to develop in accountants in a country in crisis?. The International Journal of Management Education, v. 17, p. 3, 100308.

BALLOU, B., HEITGER, D. L., \& STOEL, D. (2018). Data-driven decisionmaking and its impact on accounting undergraduate curriculum. Journal of Accounting Education, v. 44, p. 14-24.

BAO W. (2020) COVID-19 and online teaching in higher education: A case study of Peking University. Hum Behav \& Emerg Tech, v. 2, n. 2, p. 133-115.

BOROCHOVICIUS, E., \& TORTELLA, J. C. B. (2014). Aprendizagem Baseada em Problemas: um método de ensinoaprendizagem e suas práticas educativas. Ensaio: Avaliação e Políticas Públicas em Educação, v. 22, n. 83, p. 263294.

BOZKURT, A., \& SHARMA, R. C. (2020). Emergency remote teaching in a time of global crisis due to CoronaVirus pandemic. Asian Journal of Distance Education, v. 15, n. 1, p. 1-4.

CHAURASIA, S. S., KODWANI, D., LACHHWANI, H., \& KETKAR, M. A. (2018). Big data academic and learning analytics. International Journal of Educational Management. v. 32, n. 6, p. 1099-1117.

Decreto-Lei n. 2627, de 26 de dezembro de 1940 (1940). Dispõe sobre as sociedades por ações. Diário Oficial da União. Rio de Janeiro, RJ: Presidência da República.

DWIVEDI, Y. K., HUGHES, D. L., COOMBS, C., CONSTANTIOU, I., DUAN, Y., EDWARDS, J. S., GUPTA, B., LAL, B., MISRA, S., PRASHANT, P., RAMAN, R., RANA, N. P., SHARMA, S. K., \& UPADHYAY, N. (2020). Impact of COVID-19 pandemic on information management research and practice: Transforming education, work and life. International Journal of Information Management, v. 55, 102211.

DZURANIN, A. C., JONES, J. R., \& OLVERA, R. M. (2018). Infusing data analytics into the accounting curriculum: A framework and insights from faculty.

Journal of Accounting Education, v.43, p. 24-39.

FELCHER, C., VIÇOSA, C., SOARES, R., \& FOLMER, V. (2021). O uso da sala de aula invertida para ensinar polígonos. Revista de Ensino de Ciências e Matemática, v. 12, n. 1, p. 1-18.

\section{FLEISCHMAN, G. M., STEPHENSON,} T., WALKER, K. B., \& COOK, K. A. (2017). Factors that influence accounting faculty career satisfaction: Comparisons by program prestige and tenure status.

Accounting Horizons, v. 31, n. 3, p. 1-20.

GREENHOW, C., \& GALVIN, S. (2020). Teaching with social media: Evidencebased strategies for making remote higher education less remote. Information and Learning Sciences. v. 121, n. 7, p. 513524.

Lei ${ }^{\circ} 11.638$, de 28 de dezembro de 2007 (2007). Altera e revoga dispositivos da Lei no 6.404, de 15 de dezembro de 1976, e da Lei no 6.385, de 7 de dezembro de 1976, e estende às sociedades de grande porte disposições relativas à elaboração e divulgação de demonstrações financeiras. Diário Oficial da União. Brasília, DF: Presidência da República.

LOVATO, F. L., MICHELOTTI, A., \& LORETO, E. L. S. (2018). Metodologias ativas de aprendizagem: uma breve revisão. Acta Scientiae, v. 20, n. 2, p. 154171.

MARTIN, B. S., QUARESMA, V. T., \& LEAL, D. (2017). O Ensino dos CPCs nos 
Cursos de Ciências Contábeis sob a Ótica Docente e Discente: Uma Análise em Instituições de Ensino Superior (IES) da Grande Vitória. In VIII Congresso Nacional de Administração e Contabilidade-AdCont 2017.

MEURER, A. M., LOPES, I. F., ANTONELLI, R. A., \& COLAUTO, R. D. (2020). Experiências na Pós-Graduação, Comportamento nas Redes Sociais e BemEstar. Educação \& Realidade, v. 45, n. 1, p. 1-24.

NAGIB, L. D. R. C., \& SILVA, D. M. D. (2020). Adoção de metodologias ativas e sua relação com o ciclo de vida e a qualificação docente no ensino de graduação em ciências contábeis. Revista Contabilidade \& Finanças, v. 31, n. 82, p. 145-164.

NICOLA, M., ALSAFI, Z., SOHRABI, C., KERWAN, A., AL-JABIR, A., IOSIFIDIS, C., \& AGHA, R. (2020). The socio-economic implications of the coronavirus pandemic (COVID-19): A review. International journal of surgery, v. 78, n. 3, p. 185.

PINCUS, K. V., STOUT, D. E., SORENSEN, J. E., STOCKS, K. D., \& LAWSON, R. A. (2017). Forces for change in higher education and implications for the accounting academy. Journal of Accounting Education, v. 40, p. 1-18.

REBELE, J. E., \& PIERRE, E. K. S. (2019). A commentary on learning objectives for accounting education programs: The importance of soft skills and technical knowledge. Journal of Accounting Education, v. 48, p. 71-79.

RIBEIRO, M. S. S., \& SOUSA, C. M. M. (2020). Aulas Remotas e seus desafios em tempo de pandemia. Pensar a educação em pauta. Disponível em: https://pensaraeducacao.com.br/pensaraedu cacaoempauta/aulas-remotas-e-seusdesafios-em-tempo-de-pandemia/> Acesso em: 17 jan. 2021.

SILVA, F. F., AZEVEDO, Y. G. P., \& ARAÚJO, A. O. (2018). O ensino contábil na perspectiva da aprendizagem baseada em problemas. Revista Contemporânea de Contabilidade, v. 15, n. 36, p. 188-210.

SILVEIRA, S. R., BERTOLINI, C., PARREIRA, F. J., DA CUNHA, G. B., \& BIGOLIN, N. M. (2020). O Papel dos licenciados em computação no apoio ao ensino remoto em tempos de isolamento social devido à pandemia da COVID19. Série Educar - Prática Docente, v. 40, p. $35-42$.

SLEDGIANOWSKI, D., GOMAA, M., \& TAN, C. (2017). Toward integration of Big Data, technology and information systems competencies into the accounting curriculum. Journal of Accounting Education, v. 38, p. 81-93.

USAK, M., MASALIMOVA, A. R., CHERDYMOVA, E. I., \& SHAIDULLINA, A. R. (2020). New playmaker in science education: COVID19. Journal of Baltic Science Education, v. 19, n. 2, p. 180-185.

VALENTE, J. A. (2014). Blended learning e as mudanças no ensino superior: a proposta da sala de aula invertida. Educar em Revista, n. 4, p. 79-97.

VINER, R. M., RUSSELL, S. J., CROKER, H., PACKER, J., WARD, J., STANSFIELD, C., MYTTON, O., BONELL, C., \& BOOY, R. (2020). School closure and management practices during coronavirus outbreaks including COVID19: a rapid systematic review. The Lancet Child \& Adolescent Health, v. 4, n.5, p. 397-404.

WHITTLE, C., TIWARI, S., YAN, S., \& WILLIAMS, J. (2020). Emergency remote 
teaching environment: a conceptual framework for responsive online teaching in crises. Information and Learning Sciences, v. 121, n. 5, p. 311-319. 